\title{
Effect of a selected rice bran extract and a chitin synthesis inhibitor on viability of eggs of the house fly Musca domestica Linnaeus.
}

\author{
Dalia, A. M. Salem ${ }^{1}$; Nadia Helmy ${ }^{1}$; Wafaa A. $\operatorname{Radwan}^{1}$; Reda F.A. Bakr ${ }^{1 \& 2}$; \\ Noha A. Guneidy ${ }^{1}$ and Shimaa S. Mohammed. ${ }^{1}$ \\ 1-Department of Entomology, Faculty of Science, Ain Shams University, Cairo \\ 2- Biology Department, Faculty of Science, King Khalid University, Abha, Saudi Arabia
}

\section{ABSTRACT}

The efficiency of chitin synthesis inhibitor (Lufenuron), ethanolic and acetonic extracts of rice bran (Oryza sativa) were evaluated against Musca domestica eggs by direct application using topical, dipping technique and by treating vitellogenic females by both compounds.

Treatment of females with different concentrations of both compounds significantly reduce egg hatchability and the effect is dose dependent. The inhibition of egg hatching increased with increase in concentration of the compound.

Direct application of both compounds to newly laid eggs (0-15 min) of Musca domestica proved to be more effective in reducing egg hatchability especially when using dipping technique. Percentage total inhibition reached $93.04 \pm 0.57$ at $3 \mathrm{ppm}$ for Lufenuron and $100 \%$ total inhibition at $200 \mathrm{ppm}$ of acetonic extract of rice bran (Oryza sativa). This data confirm the efficiency of growth regulator derived from Oryza sativa straw and chitin synthesis inhibitor (Lufenuron). The results indicated that the acetonic extract of rice bran is significantly effective in preventing hatching than that of ethanolic extract. This is explained that the less polar the extract (acetonic) of rice bran, the more its effectiveness against eggs.

Key words: Musca domestica, chitin synthesis inhibitors, rice bran extract, viability of eggs.

\section{INTRODUCTION}

The common housefly, Musca domestica Linnaeus, 1958 (Diptera: Muscidae) is one of the dominant species found in human habitation, in tropical and subtropical regions (Slama et al., 1964; Matsumura, 1975). It has gained importance as a serious public health hazard being a vector of some infectious diseases like eye inflammation, cholera, typhoid and dysenteries.

The extensive use of chemical pesticides or insecticides resulted in inducing resistance by insect pests beside contamination of human food, mammalian toxicity, reducing beneficial non-target biota and environmental pollution. These factors have created the need for environmentally safe and specific agents for pest control purposes.

The use of botanical insecticides is dating back at least 150 years and often much longer (Monin and Nair, 2002; Wood, 2003; Philogene et al., 2005) probably with negative effects on the environment and pest resistance after application.

Over one thousand plant species contain bioactive substances many of these containing phytoecdysones, phytojuvenoids and antijuvenille hormones, which acts as IGRs (Marcard et al., 1986; Neraliya and Srivastava, 1996). Botanical extracts, termed Insect Growth Regulators (IGRs), can have a pronounced effect on the development, growth, adult emergence, fecundity, fertility, and embryogenesis resulting in effective control (Shaalan et al., 2005). The use of IGRs for housefly 
control, as an alternative approach, leads to less contamination of environment and has a good lethal effect on the insect (Yu and Terriere, 1977; Doannia et al., 1993).

Several hypotheses have been made to explain the mode of action of these IGRs including inhibition of chitin synthesis, increase in chitinase activity or inhibition of ecdysone metabolism (Meola and Mayer, 1980; Marks et al., 1982; Doannia et al., 1992).

Impairment of cuticle secretion in affected embryo may be the cause of the hatchability reduction that result from treatment with chitin synthesis inhibitors (CSI) (Grosscurt, 1978; Kostyukovsky and Trostanetsky, 2006).

Chitin synthesis inhibitors are benzoylphenylurea compounds discovered in the 1970s (Mian and Mula 1982) that interfere with insect development, disturbing the moult and resulting in deformations in the cuticle (Reynolds 1987).

The objective of this study is to evaluate the effect of selected rice bran extract (oryza sativa) and a chitin synthesis inhibitor (Lufenuron) on the viability of eggs of Musca domestica by using two methods:

a) Indirect application, by treating three days-old females with different doses of selected compounds.

b) Direct application on newly laid eggs either topically or by dipping technique.

\section{MATERIALS AND METHODS}

\section{Insect rearing:}

The housefly, Musca domestica L. was obtained from Institute of Medical Entomology, Ministry of Health, Dokki,Giza, Egypt. Both sexes were reared in wire cages with wooden frames $(30 \times 30 \times 30 \mathrm{~cm})$ at $27 \pm 1{ }^{\circ} \mathrm{C}, 60-70 \% \mathrm{RH}$, and constant light as described by Rockstein (1957) and Busvine (1962).

Tested compounds

- A chitin Synthesis inhibitor Lufenuron 10\% EC) of chemical formula:

N. [2, 5-dichloro-4-(1, 1, 2, 3, 3, 3- hexafluoroproxy)-phenyl/amino]-2,6difluorobenzamide.

- Rice bran extract (Oryza sativa)

\section{Extraction}

Rice bran of Oryza sativa was extracted by different solvents (acetone and ethanol), each extracted solvent was evaporated till dryness (Bakr et al. (2010).

\section{Application of the tested compounds:}

Female treatment:

Three days-old females (vitellogenic female) were treated with serial appropriate concentration of Lufenuron (10\%) and rice bran extract (Oryza sativa).

The adult females were fed for $24 \mathrm{~h}$ continuously on diet containing Lufenuron (10\%) or rice bran extract (Oryza sativa) at appropriate concentrations. Then, they were fed on untreated diet.

Eggs were collected daily to follow their hatchability and to study the effect of the tested compounds on the fecundity and fertility

\section{Egg treatment:}

The effect of the tested compounds on embryonic development was studied by applying them directly to egg mass either by topical application or by dipping the egg mass in an appropriate solution of the compounds to be tested. 
Newly laid eggs (0-15 minutes) postoviposition were treated topically by 0.1 , 0.5, 1, 2 and 3 ppm for chitin synthesis inhibitor (Lufenuron) and 1, 10, 100 and 200 ppm for rice bran extract $/ 30$ eggs respectively.

In dipping technique, newly laid eggs( $0-15$ minutes $)$ post-oviposition were immersed in $100 \mathrm{ml}$ water containing one of five different doses o.1, 0.5, 1, 2 and 3 ppm for chitin synthesis inhibitor and in $100 \mathrm{ml}$ water containing one of four different doses $(1,10,100$ and $200 \mathrm{ppm})$ for rice bran extract $/ 30$ eggs. The experiment was repeated 3 times (30x3). Eggs were dipped for 1 minute in each solution.

\section{Evaluation of tested compounds:}

The effect of tested compounds on the viability of the eggs, were determined by counting the number of unhatched eggs 24 hours after deposition or treatment (about 16 hours after the time they would normally hatch).

\section{Statistical Analysis:}

The obtained data were manipulated statistically with SPSS version 16 . While probabilities (p) were carried out using STATISTICA version 6 and AVOVA, Duncan multiple range test $(\mathrm{p}<0.01)$. The level of significance was expressed as highly significant $(\mathrm{p} \leq 0.001)$, significant $(\mathrm{p} \leq 0.05)$ and non - significant $(\mathrm{p}>0.05)$.

\section{RESULTS}

\section{1) Effect of different doses of Lufenuron on viability of eggs laid by treated} Musca domestica females .

Musca domestica females at $3^{\text {rd }}$ day of emergence were fed for $24 \mathrm{hr}$ on diet containing Lufenuron at appropriate concentrations (0.005, 0.01, 0.1 and $0.5 \mathrm{ppm})$. The eggs from normal and treated females were examined for their hatchability.

Data on Table (1) indicate that treatment of Musca domestica females with Lufenuron exhibit a significant effect on viability of eggs laid, where percentage of unhatched eggs increase significantly $(\mathrm{P}<0.01)$ with increasing dose.

Table 1: Effect of different doses of lufenuron on viability of eggs laid by treated Musca domestica females at $3^{\text {rd }}$ day of emergence.

\begin{tabular}{|c|c|c|c|}
\hline Conc. (ppm) & \% Total eggs laid & $\begin{array}{c}\text { \% Hatched eggs } \\
\text { (\% Fertility) }\end{array}$ & \% Unhatched eggs \\
\hline $\mathbf{0 . 0 0 5}$ & $67.9 \pm 1.58^{\mathrm{b}}$ & $97.53 \pm 1.14^{\mathrm{a}}$ & $1.46 \pm 0.12^{\text {cd }}$ \\
\hline $\mathbf{0 . 0 1}$ & $58.76 \pm 1.02^{\mathrm{c}}$ & $97.1 \pm 0.97^{\mathrm{a}}$ & $2.6 \pm 0.15^{\mathrm{c}}$ \\
\hline $\mathbf{0 . 1}$ & $43.43 \pm 1.48^{\mathrm{d}}$ & $88.3 \pm 1.21^{\mathrm{b}}$ & $13.03 \pm 0.4^{\mathrm{b}}$ \\
\hline $\mathbf{0 . 5}$ & $37.7 \pm 1.68^{\mathrm{e}}$ & $79.63 \pm 0.47^{\mathrm{c}}$ & $20.9 \pm 0.54^{\mathrm{a}}$ \\
\hline Control & $99.3 \pm 0.75^{\mathrm{a}}$ & $99.7+0.27^{\mathrm{a}}$ & $0.23 \pm 0.05^{\mathrm{d}}$ \\
\hline
\end{tabular}

* Data are presented as mean $\pm \mathrm{SE}$

* Means bearing different letters within column are significantly different $(\mathrm{P}<0.01)$ ANOVA, Duncan multiple range test.

The percentage of unhatched eggs was $(1.46 \pm 0.12,2.6 \pm 0.15,13.03 \pm 0.4$ and $20.9 \pm 0.54)$ for $(0.005,0.01,0.1 .0 .5 \mathrm{ppm})$ Lufenuron concentration, respectively compared with $0.23 \pm 0.05$ for the control (normal eggs). Whereas, the percentage of hatched eggs (fertility) decreases significantly $(\mathrm{P}<0.01)$ with increasing concentraion used. However, there is no significant effect on fertility for females fed on diet containing 0.005 and 0.01 ppm Lufenuron.

2) Effect of different doses of Ethanolic and Acetonic rice bran on viability of eggs laid by treated Musca domestica females .

Musca domestica females at $3^{\text {rd }}$ day of emergence were fed for $24 \mathrm{hr}$ on diet containing appropriate concentration of ethanolic and acetonic extract of rice bran 
$(10,50,100$ and $150 \mathrm{ppm})$. The eggs from normal and treated females were examined for their hatchability.

Data on Table (2) indicate that treatment of Musca domestica females with ethanolic and acetonic extract of rice bran exhibit a significant effect on viability of eggs laid by female,where the percentage of unhatched eggs increases significantly $(\mathrm{P}<0.01)$ with increasing dose. The percentage of unhatched eggs was $(0.49 \pm 0.08$, $1.4 \pm 0.14,5.76 \pm 0.11$ and $10.16 \pm 0.9)$ for $(10,50,100$ and $150 \mathrm{ppm})$ of ethanolic extract of rice bran concentration, respectively compared with $0.2 \pm 0.05$ for control. The acetonic extract showed higher effectiveness on percentage of unhatched eggs than that of ethanolic extract.It ranges from $(0.93 \pm 0.21$ to $18.1 \pm 0.94)$ for $(10$, to 150 $\mathrm{ppm}$ ) of acetonic extract concentration, respectively. Generally, the effect of plant extract (either ethanolic or acetonic) is the highest at 150ppm concentration.

Table 2: Effect of different doses of Ethanolic and Acetonic extract of rice bran on viability of eggs laid by treated Musca domestica females at $3^{\text {rd }}$ day of emergence.

\begin{tabular}{|c|c|c|c|c|c|c|}
\hline $\begin{array}{c}\text { Conc. } \\
\text { (ppm) }\end{array}$ & \multicolumn{2}{|c|}{$\%$ Total eggs laid } & \multicolumn{2}{c|}{$\begin{array}{c}\text { \% Hatched eggs } \\
\text { (\% Fertility) }\end{array}$} & \multicolumn{2}{c|}{ \% Unhatched eggs } \\
\hline & Ethanolic & Acetonic & Ethanolic & Acetonic & Ethanolic & Acetonic \\
\hline $\mathbf{1 0}$ & $89.6 \pm 0.185^{\mathrm{b}}$ & $67.23 \pm 1.11^{\mathrm{b}}$ & $99.23 \pm 0.12^{\mathrm{a}}$ & $99 \pm 0.15^{\mathrm{ab}}$ & $0.49 \pm 0.08^{\mathrm{e}}$ & $0.93 \pm 0.21^{\mathrm{c}}$ \\
\hline $\mathbf{5 0}$ & $79.23 \pm 0.38^{\mathrm{c}}$ & $56.9 \pm 0.94^{\mathrm{c}}$ & $98.36 \pm 0.187^{\mathrm{a}}$ & $97.93 \pm 0.21^{\mathrm{b}}$ & $1.4 \pm 0.14^{\mathrm{c}}$ & $2.23 \pm 0.38^{\mathrm{e}}$ \\
\hline $\mathbf{1 0 0}$ & $74.1 \pm 0.44^{\mathrm{d}}$ & $48.16 \pm 0.91^{\mathrm{d}}$ & $94.5 \pm 0.25^{\mathrm{b}}$ & $89.16 \pm 0.42^{\mathrm{c}}$ & $5.76 \pm 0.11^{\mathrm{b}}$ & $11.76 \pm 0.61^{\mathrm{b}}$ \\
\hline $\mathbf{1 5 0}$ & $66.96 \pm 1.47^{\mathrm{e}}$ & $35.5 \pm 1.24^{\mathrm{e}}$ & $89.76 \pm 0.88^{\mathrm{c}}$ & $83.16 \pm 0.41^{\mathrm{d}}$ & $10.16 \pm 0.9^{\mathrm{a}}$ & $18.1 \pm 0.94^{\mathrm{a}}$ \\
\hline Control & $99.3 \pm 0.75^{\mathrm{a}}$ & $99.43 \pm 0.29^{\mathrm{a}}$ & $99.56 \pm 0.27^{\mathrm{a}}$ & $99.56 \pm 0.27^{\mathrm{a}}$ & $0.2 \pm 0.05^{\mathrm{d}}$ & $0.2 \pm 0.05^{\mathrm{d}}$ \\
\hline
\end{tabular}

*Data are presented as mean $\pm \mathrm{SE}$

* Means bearing different letters within column are significantly different $(\mathrm{P}<0.01)$ ANOVA, Duncan multiple range test.

The percentage of hatched eggs (fertility) decreases significantly $(\mathrm{P}<0.01)$ with increasing dose (Table 2) However, there is no significant effect on percentage fertility for females fed 10 and $50 \mathrm{ppm}$ of ethanolic and acetonic extract of rice bran.

The percentage of hatched eggs was $(99.23 \pm 0.12,98.36 \pm 0.18,94.5 \pm 0.25$ and $89.76 \pm 0.88)$ for $(10,50,100$ and $150 \mathrm{ppm})$ ethanolic extract of waste product concentration, respectively compared with $99.56 \pm 0.27$ for control. The Acetonic extract showed higher effectiveness than that of ethanolic extract on percentage of hatched eggs (fertility). It ranges from $(99 \pm 0.15$ to $83.16 \pm 0.41)$ for $(10$ to $150 \mathrm{ppm})$ of acetonic extract of waste product concentration, respectively.

\section{3) Effect of direct application of Lufenuron on viability of eggs:}

\subsection{Topical application:}

In this experiment, newly laid eggs $(0-15 \mathrm{~min})$ postoviposition were treated topically with five different doses of Lufenuron (0.1, 0.5, 1, 2 and $3 \mathrm{ppm} / \mathrm{egg}$ mass). Thirty eggs were used for each dose and the experiment was repeated three times.

Results on Fig. (1) indicate that there is a significant effect of the compound on treated eggs $(p<0.05)$. This effect was dose-dependent, where percentage of unhatched eggs increases with increasing dose. The effect is most pronounced in case of using 2 and $3 \mathrm{ppm}$ where percentage of unhatched eggs were $43.4 \pm 4.6$ and $70.1 \pm 0.12$ respectively.

\subsection{Dipping technique:}

Newly laid eggs (0-15 min) were immersed in $100 \mathrm{ml}$ of distilled water containing one of five different doses $(0.1,0.5,1,2$ and $3 \mathrm{ppm} / 30$ eggs $)$ of Lufenuron.

Thirty eggs were used for each dose and the experiment was repeated three times. Eggs were dipped for 1 minute in each solution. 
Results on and Fig. (1) showed that dipping the the eggs in 0.1, 0.5, 1, 2 and 3 ppm Lufenuron solution has a highly significant effect $(\mathrm{P} \leq 0.01)$ on eggs,increased with increasing dose; where percentage of unhatched eggs were16.7 $\pm 6.3,26.7 \pm 6.5$, $33.3 \pm 5.7,45.1 \pm 5.7$ and $74.1 \pm 0.57$ for Lufenuron concentrations $(0.1,0.5,1,2$ and 3 ppm), respectively compared with $3.3 \pm 0.57$ for the control.

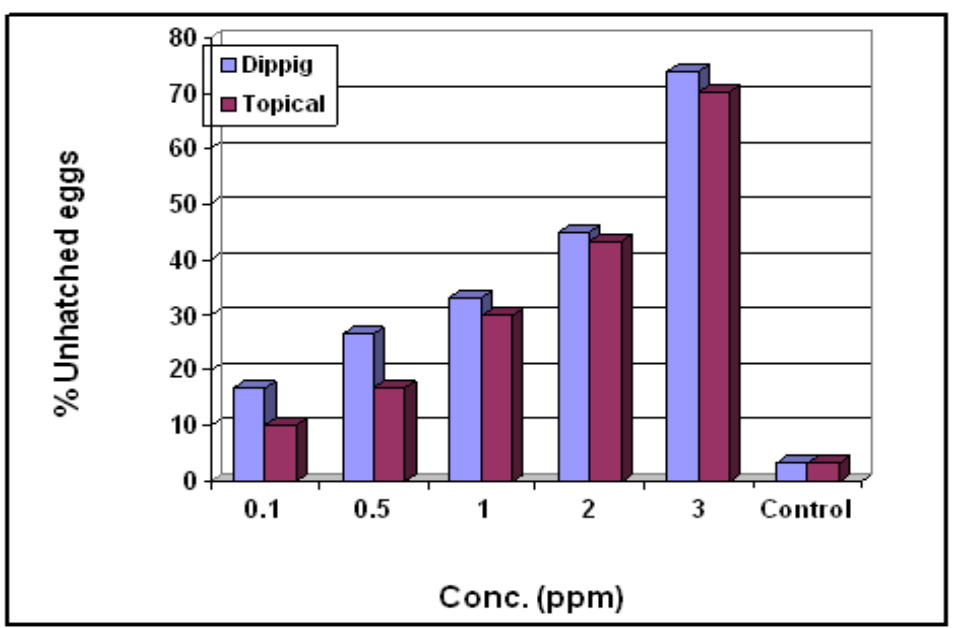

Fig. 1: Hatchability of Musca domestıca eggs treated topıcally and by dippıng tecnnıque with different doses of Lufenuron at (0-15) min after deposition.

It is of interest to mention that a number of hatched eggs were abnormal, therefore we estimate $\%$ total inhibition by adding $\%$ unhatched to $\%$ of abnormal hatched.

\section{4) Effect of direct application of Ethanolic and Acetonic rice bran extract on} viability of eggs:

\subsection{Topical application:}

In this experiment,newly laid eggs $(0-15 \mathrm{~min})$ were treated topically with four different doses of ethanolic and acetonic extract (1, 10, 100 and $200 \mathrm{ppm} / \mathrm{egg}$ mass). Thirty eggs were used for each dose and the experiment was repeated three times.

Results on Fig. (2) indicate that ethanolic extract has a significant effect on treated eggs $(\mathrm{P}<0.05)$ and the effect was dose-dependent increased with increasing concentration, where percentage of unhatched eggs were $(20 \pm 5.77,30 \pm 5.76$, $39.8 \pm 5.76$ and $46.6 \pm 5.19)$ for concentration $(1,10,100$ and $200 \mathrm{ppm}$ ), respectively compared with $3.3 \pm 0.57$ for the control.

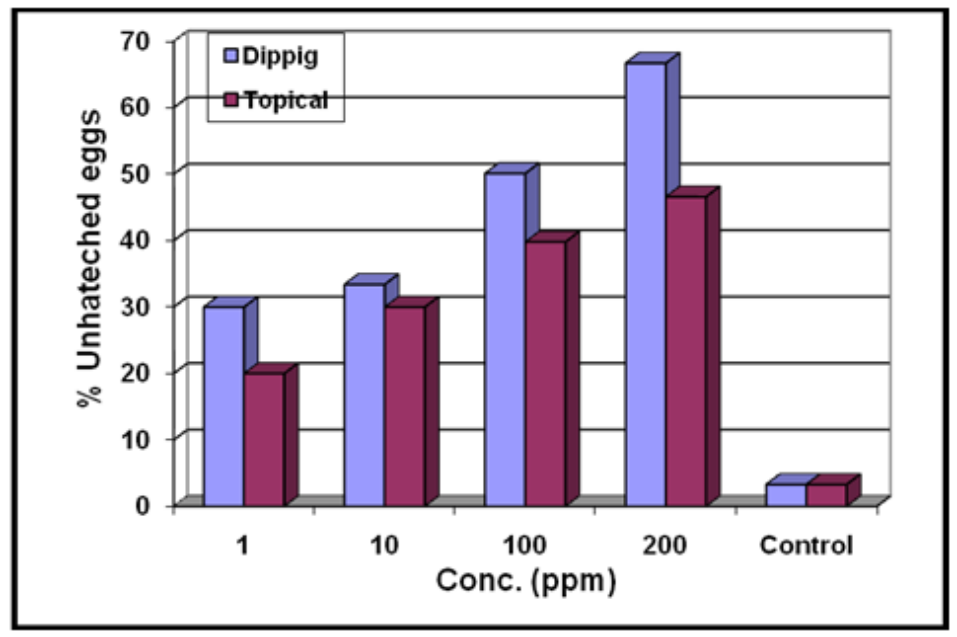

Fig. 2: Hatchability of Musca domestica eggs treated topically and by dipping technique with different doses of Ethanolic extract of rice bran (Oryza sativa) at (0-15) min after deposition. 
Results on and Fig. (3) indicate that acetonic extract has a highly significant effect on treated eggs $(\mathrm{P} \leq 0.01)$, where percentage of unhatched eggs were $(31 \pm 5.77$, $40 \pm 5.77,43.4 \pm 5.19$, and $87.7 \pm 1.27$ ) for concentration (1, 10, 100 and $200 \mathrm{ppm}$ ), respectively compared with $3.3 \pm 0.57$ for the control.

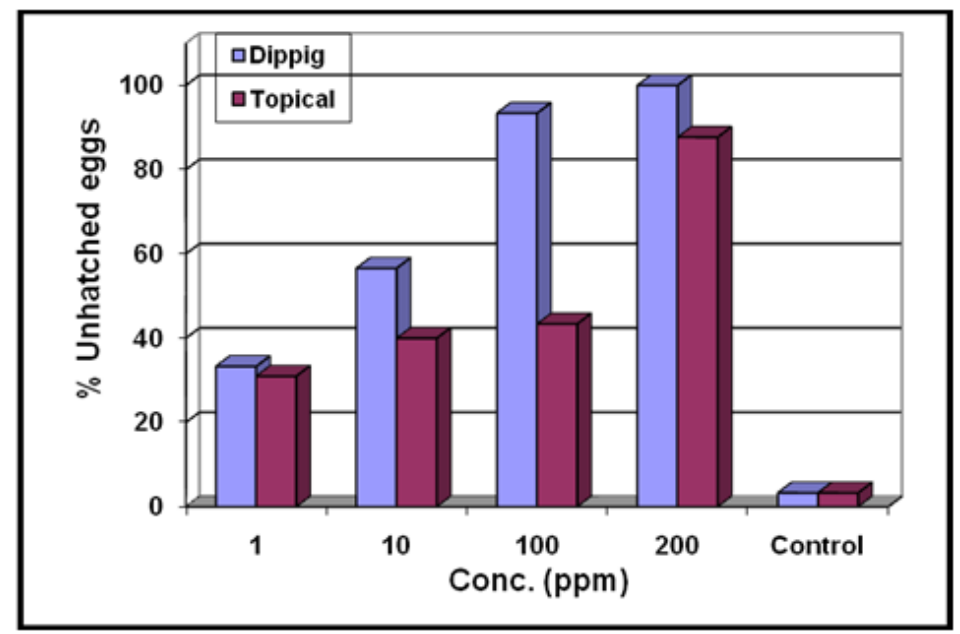

Fig. 3: Hatchability of Musca domestica eggs treated topically and by dipping technique with different doses of Acetonic extract of rice bran (Oryza sativa) at ( 0-15) min after deposition.

\subsection{Dipping technique:}

Newly laid eggs (0-15 min) were immersed in $100 \mathrm{ml}$ of distilled water containing one of four different doses $(1,10,100$ and $200 \mathrm{ppm} / 30 \mathrm{eggs})$ of ethanolic and acetonic rice bran extract.

Thirty eggs were used for each dose and the experiment was repeated three times. Eggs were dipped for 1 minute in each solution.

Results from and Fig. (2) showed that dipping the the eggs in solution containning $1,10,100$ and $200 \mathrm{ppm}$ of ethanolic rice bran extract has a highly significant effect $(\mathrm{P} \leq 0.01)$ on eggs; the effect was dose - dependent .Percentage of unhatched eggs were $(30 \pm 5.7,33.4 \pm 6.3,50.1 \pm 6.5$ and $66.7 \pm 6.3)$ for concentration $(1,10,100$ and 200 ppm ), respectively compared with $3.3 \pm 0.57$ for the control.

Results on and Fig. (3) showed that dipping the eggs in solution containning different concentrations of acetonic waste extract has a highly significant effect $(\mathrm{P} \leq 0.01)$ on eggs. The percentage of unhatched eggs were $(33.3 \pm 6.3,56.6 \pm 5.77$, $93.4 \pm 0.57$ and 100$)$ for concentration $(1,10,100$ and $200 \mathrm{ppm})$, respectively compared with $3.3 \pm 0.57$ for the control.

From this result,it is clear that acetonic extract showed higher effectiveness on reducing hatching (viability) of eggs than that of ethanolic extract. Generally, the effect of rice bran extracts (either ethanolic or acetonic) is the highest at 200ppm concentration.

\section{DISCUSSION}

1)Effect of different doses of Lufenuron and a rice bran extract on viability of eggs laid by treated Musca domestica females.

The present study revealed that feeding vitellogenic females $\left(3^{\text {rd }}\right.$ day of emeregence) of Musca domestica on different concentrations of the chitin synthesis inhibitor (Lufenuron) and two extracts (ethanolic and acetonic) of a waste product (Oryza sativa) reduce the viability of eggs that was manifested as an impairment of egg hatchability. Musca domestica oogenesis is classified into three stages 
previtellogenic, vitellogenic stage (at $3^{\text {rd }}$ day after emerege) and ovulation stage (Just before egg laying) (Shanbaky et al. 1993). Vitellogenic females (3-days) of Musca domestica are the most sensitive to the effect of different insect growth regulator (Siriwattanarungsee et al. 2008, Shanbaky et al. 1993).

Reduction of female fertility after feeding on chitin synthesis inhibitor has been also reported for different insect species; Colorado potato beetles Leptinotarsa decemlineata fertility and fecundity were reduced after feeding on plant treated with Novaluron (Alyokhin et al. 2008). Fecundity and egg viability of Coptotermes formasonus was lowered after treatment with Lufenuron (Rojas and Morales-Ramos, 2004). Reduction of egg hatch has been reported in Blattella germanica after feeding on bait containing $0.25 \%$ Diflubenzuron (Koehler and Patterson, 1989), Ctenocephalides felis after adult feeding on 0.125 and $1 \mathrm{ppm}$ of Lufenuron (Meola et al. 1999).

As early as (1976) Grosscurt recorded that topical application of adult Musca domestica with Diflubenzuron inhibit egg hatching.

Wolfenbarger and Nemec (1991) also reported that egg hatch was highly reduced in A. grandis grandis after females being treated with Diflubenzuron or Penfluron.

According to Wilson and Cryan (1997) Lufenuron has a dramatic effect on the viability of eggs oviposited by females Drosophila melanogaster transferred to lufenuron food. This effect of Lufenuron on egg fertility is reversible after transfer of the adult to regular food for nearly a week.

Failure of hatching was explained by Wilson and Cryan (1997) that the complete embryos were unable to perforate the surrounding membrane, probably due to a weakened chitinous mouth hook assembly that was insufficiently rigid to effect hatching.

On the other hand, Hami et al. (2004) explained the effect of Flucycloxuron on viability of eggs of Tenebrio molitor as it reduces the thickness of chorion from freshly laid eggs.

Findings of the present study indicate that feeding vitellogenic Musca domestica females on different concentrations of ethanolic and acetonic extract of rice bran, Oryza sativa has a significant effect on viability of laid eggs. Similar results were recorded, using different plant extracts for different insect species; Fertility of Locusta migratoria were reduced after treatment of newly emerged females with methanolic extract of leaves and stems of Haplophyllum tuberculatum (Acheuk et al. 2012). The number of eggs laid per female and egg viability of Spodoptera littoralis was reduced after treatment with $2 \%$ suspension of ground seed of $\underline{A}$. indica (El-sayed, 1982).

Mostafa (1993) also reported the reduction of Fertility of Trogoderma granarium after treatment with three plant extracts. Complete inhibition of hatchability was achieved by the action of Piper nigrum extract.

2) Effect of direct application of Lufenuron and rice bran extract on viability of eggs by topical and dipping techniques:

From the present study,topical application of different doses of Lufenuron, and ethanolic and acetonic extracts of rice bran, Oryza sativa, have a significant effect by inhibiting the development of Musca domestica eggs treated (0-15min) postovipotion.

This is also the case with several insect growth regulators; Direct application of Dimilin, Methoprene and hydroprene on the eggs of Musca domestica caused a decrease in the rate of hatching (Lineva and Chunina, 1979). Exposing the eggs of culex quinquefasciation to Sir 8514 also decrease viability of eggs; younger embryos (0.5-4.5 hours) were the most sensitive (Miwra \& Takahasli 1979). Similar 
observations occurred with Marchiondo et al.(1990), Adham and Shoukry (1984) and Saenz et al. (2006), Sharaby (1988) found that spraying 2\% concentration of essential oil and lemon grass Cymbopogen citratiis on spodoptera eggs caused inhibition of hatching. The topical application of adult females Boophilus microplus with Melia azedarach extract caused a partilliy or totally inhibition of egg productions and embryogenesis (Borges et al. 2003). This was also observed with Savolainen et al. (1995), Gajmer et al. (2002) and Cabral et al. (2007).

In the present study, immersion of newly deposited eggs (0-15 min) of Musca domestica in Lufenuron, ethalonic and acetonic extracts of rice bran, Oryza sativa solution of different concentrations for $1 \mathrm{~min}$ have a highly significant effect in reducing egg viability. Similary, dipping of phytoseilus persimilis eggs in 100ppm of Kenoprene, Methoprene and Hydroprene inhibit egg hatching by 100\% (Mandanlar and Kismali,1994). Dipping technique proved also to be effective in treatment of Acheta domestica eggs with Dimataf and Diflubenzuion that show a good ovicidal effect on treated eggs (Matolin and Chwakova, 1983), and the same was observed in treatment of leptinotarsa decemlineata eggs dipped in Novaluron solution (Alyokin et al., 2008).Sharma and Bhargaua (2001) recorded ovicidal effect of some growth disrupting compound present in neem, undi (Calophyllum inophyllum), karanj (Pongania glabra) lemon grass oil $(0.25,0.5,1,2,3$ and $5 \%$ ) were applied on eggs of Cocyra cephalonica by dipping method. Dipping of eggs of Myllocerus undecimpustulatus in 1\% concentration of neem extract and undi extract resulted in $100 \%$ and $94.66 \%$ egg mortality (Agarwal, 1990). Similar results were observed with Dwivedi and Kumar (1999), Dwivedi and Gang (2000) and Kumar and Jain (2004).

It is observed also that the acetonic extract of waste product seemed to be significantly effective in preventing hatching than that of ethanolic extract. This indicates that the less polar the extract (acetonic) of rice bran, the more its effectiveness against eggs (Borges et al. 2003).

Results of the present work suggest that topical application seem not to permit enough amount of the tested compounds to penetrate through the chorion of the egg; where the compounds could have been evaporated and the time for penetration may be short. However, dipping technique appears to allow a better chance and enough time for the tested compound in the solvent to penetrate and pass into the contents of the egg. Egg immersion in the tested compounds enabled penetration to occur through the whole surface of the egg (including the micropyle) during the time of immersion (1min) and afterwards.

\section{REFERENCES}

Acheuk, F.; Cusson, M. and Doumandji - Mitiche, B. (2012): Effects of methanolic extract of the plant Haplophyllum tuberculatum and of Teflubenzuron on female reproduction in the migratory Locust, locusta migratoria (Orthoptera: Oedipodinae). Journal of Insect physiology., 58: 335-341.

Adham, F.K. and Shoukry, A. (1984): Juvenile hormone analogues; effect on eggs of Aedes cospius pallas (Diptera: Culicidae). J. Egypt. Soc. Parasitol., 14(2):525530.

Agarwal, I.L. (1990): Ovicidal activity of some phytochemicals on Myllocerus undecimpustulatus Faust. Indian J. Ent., 52: 35-38

Agarwal, I.L. (1990): Ovicidal activity of some phytochemicals on Myllocerus undecimpustulatus Faust. Indian J. Ent., 52: 35-38. 
Alyokhin, A.; Sewell, G. and Chobam, R. (2008): Reduced viability of colorado potato beetle, Leptinotarsa decemlineata, eggs exposed to Novaluron. Pest .Manag. Sci., 64(1): 94-99

Bakr, R.F.A.; Helmy, N.; Namwr, G.A.; El Ibrahim S. and Helmy, O.M. (2010): Changes in protein content of Culex pipiens mosquito treated with two argiculture waste extracts. Egypt. Acad. J. Biolog. Sci. 3(1): 95-103.

Borges, L.M.F.; Ferri, P.H.; Silva, W.J.; Silva, W.C. and Silva, J.G. (2003): In vitro efficacy of extract of Melia azedarach against the tick Boophilus microplus. Med. Vet. Entomol., 17:228-231.

Busvine, J.R. (1962): A Laboratory technique for measuring the susceptibility of houseflies and blow flies to insecticides. Lab. Prot., 11: 404-468.

Cabral, M.M.; Mendonca, P.M.; Gomes, G.M.; Barbosa- Fitho, J.M.; Dias, C.S.; Soares, M.J. and Queiroz, M.M. (2007): Biological activity of yangambin on the post embryonic development of Chrysoma megacephala (Diptera: Calliphoridae), J. Med. Entomol. 44(2): 249-255.

Doanina, J.M.; Dossou - Yovo, J.; Duval, J. and Guilet, P. (1993): Factors affecting the efficacy of two growth regulator conlpounds OMS 3010 (phenoxycarb) and OMS 3019 (Ethoxypridine), on larvae of the simulium damnosum complex. Ann. Soc. Belg. Med. Trop., 73: 119 - 125.

Doanina, J.M.; Dossou - Yovo, J.; Duval, J. and Hougard, H. (1992): small scale evaluation of the efficacy of growth regulating insecticides on larvae of simuliurn damnosurn complex (Diptera: simuliidae). Ann. Soc. Belg. Med. Trop., 27: 197-203.

Dwivedi, S.C. and Garg, S. (2000): Citrus cleam. A promising ovicide against Corcyra cephalonica (Staintan), Insect Environ., 5(4): 155-156

Dwivedi, S.C. and Kumar, A. (1999): Ovicidal activity of 6 plant extracts on the eggs of Corcyra cephalonica (Stainton) (Lepidoptera: Pyralidae). UPJ of Zool., 19(3): 175-178.

El- Sayed, E.I. (1982): Evalution of the insecticidal properties of the common indian neem Azadirachta indicar seeds against the Egyptian cotton leaf worm Spodoptera littoralis (Boisd). Bull. Ent. Soc. Egypt, Econ. Ser., 13:39-47.

Gajmer, T.; Singh, R.; Saini, R.K. and Kalidhar, S.B. (2002): Effect of methanolic extracts of neem (Azadirachta indica A.Juss) and bakain (Melia azedarach L.) seeds on oviposition and egg hatching of Earias Vittella (lep., Noctuidae). J. AppL. Entomol., 126:238-243.

Grosscurt, A.C. (1976): Diflubenzuron: Some aspects of its ovicidal and larvicidal mode of action and an evaluation of its practical possibilities. Pestic. Sci., 9: 373-386.

Grosscurt, A.C. (1978): Effects of diflubenzuron on mechanical penetrability, chitin formation and structure of the elytra of Leptinotarsa decemliniata. J. Insect. Physiol., 24(12):827-831.

Hami, M.; Taibi, F. and Soltani-Mazouni, N. (2004): Effects of Flucycloxuron, a chitin synthesis inhibitor, on Reproductive events and thickness of chorion in Mealworms. Comm. Appl. Bio. Sci. Ghent university., 69(3): 249-255.

Koehler, P.C., and Patterson, R.S. (1989): Effects of chitin synthesis-inhibitors on German cockroach (Orthoptera: Blattellidae) mortality and reproduction. J. Econ. Entomol., 82(14):3-148.

Kostyukovsky, M. and Trostanetsky, A. (2006): The effect of a new chitin synthesis inhibitor, novaluron, on various developmental stages of Tribolium castaneum (Herbst). J. of stores products Research, 42: $136-148$. 
Kumar, V. and Jain, K.L. (2004): Growth regulatory effects of Neem against $C$. cephalonica. Indian J. Appl. Ent., 18(1): 73-74.

Lineva, V.A. and Chunina, L.M. (1979): The effect of insect development inhibitors Dimilin, Altosid and Altozor on houseflies (Musca domestica). I. The effect of development inhibitors on housefly eggs. Neditsinskaya- parazitologiya Bolwzni., 48(6):60-64.

Madanlar, N. and Kismali, S. (1994): Effects of some juvenile hormone analogues on the egg hatching and postembryonic development of Phytoseiulus persimilis Athias- Henriot (Acarina: Phytoseiidae). Ege. Uni. Ziraak. Fakuites ,Bitlei. Kotuma. Bolumu. Izmir., 539-548:25-28.

Matolin, S. and Chudakova, I.V. (1983): Ovicidal effects of diflubenzuron and dimatif on eggs of Acheta domestica (Orthoptera). Acta. Entomol. Bohemoslov., $80: 352-355$.

Marcard, M.; Zebitz, C.P.W. and Schnlutterer, H. (1986): the effect of crude 111ethanol extracts of A jupa spp on postembryonic development of different 1110Squito species J. Appl. Entonlol., 101: 146-154.

Marchiondo, A.A.; Ringer, J.L.; Sonenshine, D.E.; Rowe, K. and Slusser, J.H. (1990): Ovicidal and larvicidal modes of action of fenoxycarb against the cat flea (Siphonoptera: Pulicidae). J.Med. Entomol., 27(5):913-921.

Marks, E.P.; Leighton, T. and Leighton, F. (1982): Modes of action of Chitin Synthesis inhibitors. In: Insecticide Mode of Action. J.R. Coats, ed. Academic Press, New York, pp. 281-313.

Matsamura, F. (1975): Toxicology of insecticides. New York|: Plenum.1378.

Meola, R.W.; Dean, S.R.; Meola, S.M.; Sittertz-Bhatkm, H. and Schenker, R. (1999): Effect of lufenuron on chorionic and cuticular structure of unhatched larval Ctenocephalides felis (Siphonaptera: Pulicidae). J. Med. Entomol.,

Meola, S.M. and Mayer, R.T. (1980): Inhibition of cellular proliferation of in 1aginal epidermal cells by Diflubenzuron on pupae of the stable fly. Sci (wash). 207 (4434): 985 - 987.

Mian LS and Mulla MS. (1982): Biological and environmental dynamics of insect growth regulators (IGRs) as used against Diptera of public health importance. Residue Rev 84: 27-112.

Miura,T.and Takahashi,R.M.(1979):Effects of the insect growth inhibitor SIR-8514 on hatchability of southern house mosquito eggs. J.Econ.Entomol., 72:692-694.

Monin, R.A. and Nair, M.G. (2002): pest managing efficacy of trans - asarone isolated from Daucus carota L seeds. J. Agric. Food. Chel11., 50 : 4475 - 8.

Mostafa, T.S. (1993): Efficiency of certain naturally occurring plant extracts aginst Trogoderma granagium (Coleoptera: Dermestidae). J. Egypt. Ger. Soc., 12(D):227-238.

Neraliya, S. and Srivastava, U.S. (1996): Effect of plant extracts on posten1bryonic development of the mosquito culex quinquefasciatus. J. Adv. Zool., 17: 54 - 58.

Philogene, B.J.R; Regnault - Rogen, C. and Vincent, C. (2005): Botanicals: yesterday's and today's pronlises. In: Regnault - Rogen C, philogene, B. J. R., Vincent C, editors: Biopesticides of plant origin. Paris, France: lavoisier, PP. 115. Reynolds SE 1987. The cuticle, growth and moulting in insects: the essential background to the action of acylurea insecticides. Pest Sci 20: 131-146.

Reynolds SE (1987). The cuticle, growth and moulting in insects: the essential background to the action of acylurea insecticides. Pest Sci 20: 131-146. 
Rockstein, M. (1957): Longevity of male and female houseflies. J. Geront. 12: 253256.

Rojas, M.G. and Maroles- Ramos, J.A. (2004): Disruption of Reproductive activity of Coptotermes formosanus (Isoptera: Rhinotermitidae) primary reproductives by three chitin Synthesis inhibitors. J. Ecom. Entomal., 97(6):2015-2020.

Saénz de Cabezan, F.J.; Pérez- Moreno, I.; Zalom, F.G. and Marca, V. (2006): Effects of Lufenuron on Lobesia botrana (Lepidoptera: Torticidae) egg, Larval and adult stages, J. Ecom. Entomol. 99(2): 421-31.

Savolainen, V.; Wuest, J.; Lafont, R. and Connat, J.L. (1995): Effects of ingested phytoecdysteroids in the female soft tick Ornithodoros moubata. Experientia., 51(6):596-600.

Shaalan, E.A.; canyon, D.; Younes, M.W.F.; Abdel Wahab, H. and Mansour, A.H. (2005): A review of botanical phytochemicals with mosquitocidal potential. Environment international., 31: 1149 - 1166 .

Shanbakey, N.M; Enan, R.A; Radwan, W.A. and Hasaneen, H. E. (1993): Effect of juvenile hormone analogue on embyronic and postembryonic development of Musca domestica (L.). $18^{\text {th }}$ international conference for statistics, computer science, scientific and social applications Cairo, Egypt, pp. 169-190.

Sharaby, A. (1988): Anti- insect properties of the essential oil of lemon grass, cymbopogon citratus against the lesser cotton leaf worm spodoptera exigue (Hbn). Insect Sci. Appli., 9(1): 77-80.

Sharma, K.C. and Bhargava, M.C. (2001): Ovicidal effect of some growth disrupting compounds on rice moth, C. cephalonica, (Stain ton) (Lepidoptera: Pyralidae), Indian J Appl. Ent., 15(1): 24-28

Siriwattanarungsee, S.; Sukontason, K.L. and Olson, J.K. (2008): Efficacy of neem extract against the blowfly and housefly. Parasitol. Res., 103: 535-544.

Slama, K.; Romanuk, M. and Sortn, F. (1964): Insect hormones and bio analogues (N. Y.: springer).

Wilson, T.G. and Cryan, J.R. (1997): High genetic variability in Drosophila melanogaster for susceptibility to lufenuron, a chitin synthesis inhibitor insecticide. In: Molecular Genetics and Evolution of Pesticide Resistance. T.M. Brown, ed. American Chemical Society, Series 6-45, Washington, DC, pp. 141-148.

Wolfenbarger, D.A. and Nemec, S.J. (1991): Usefulness of two diphenzyl benzoyl urea insect growth regulators against the boll weevil (Coleoptera: Curculionidae). J. Entomol. Sci. 26: 466-473.

Wood, A. (2003): compendium of pesticide common names: Insecticides. http://www.alanwood.net/pesticides/index. html; 2003 (accessed 8103) world health organization. Instructions for determining the susceptibility or resistance of mosquito larvae to insecticides; 1981. (WHO/VBC/8/.807.).

Yu. S.J. and Terriere, L.C. (1977): Ecdysone metabolism by soluble enzymes from three species of Diptera and its inhibition by the insect growth regulator TH 6040. Pestic Biochem. Physiol., 7: 48 - 55. 


\section{ARABIC SUMMARY}

\section{تأثير مستخلص نخالة الأرز وإحدى مثبطات الكيتين على حيوية البيض فى الذبابة المنزلية}

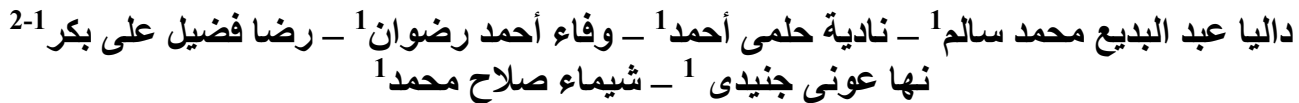

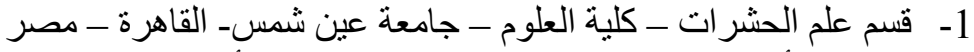

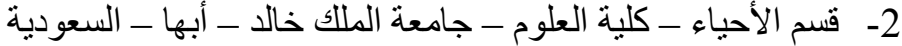

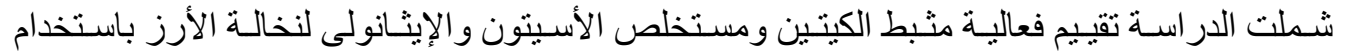

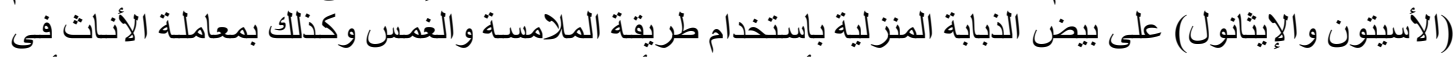

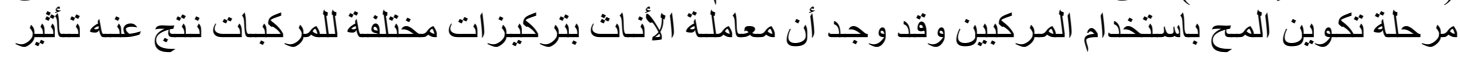

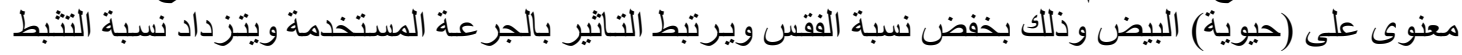

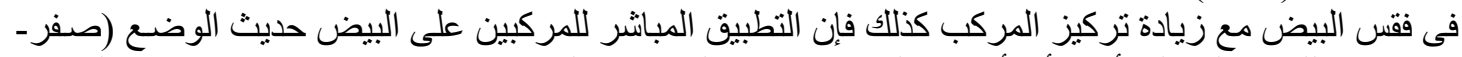

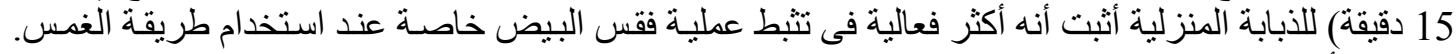

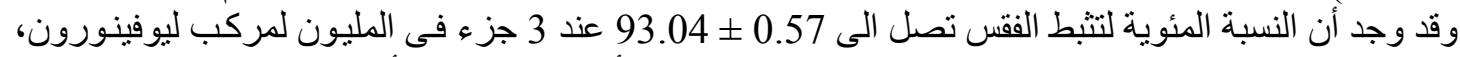

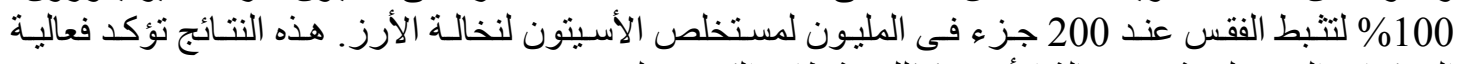
المركبات المستخلصة من نخالة الأرز وكذلك مثبطات الكيتين (ليو فينورون).

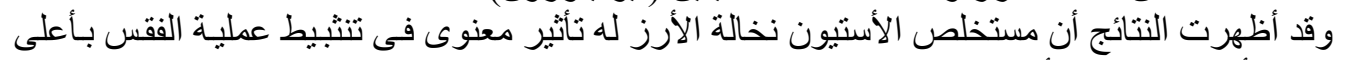

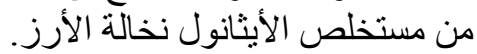
و هذا يمكن تفسيره بأنه كلما كان المركب الأقل قطبية (الأسيتون) لنخالة الأرز كان تأثيره أعلى على 